\title{
Exploring Risk Factors with Ventilator Associated Pneumonia among Infants in Intensive Care Units
}

\author{
FATMA E. DAGHER, M.Sc.*; AZZA A. ATTIA, M.D.*; NAGLAA F. MAHMOUD, M.D.* and \\ AHMED M. BADR, M.D.** \\ The Department of Pediatric Nursing, Faculty of Nursing* and The Department of Pediatric Medicine, Faculty of Medicine**, \\ Cairo University, Egypt
}

\begin{abstract}
Background: Ventilator Associated Pneumonia (VAP) is defined as pneumonia occurring more than 48 hours after child is intubated and ventilated mechanically; VAP is the second most common hospital-acquired infection in pediatric Intensive Care Units, which linked to increased morbidity, mortality, lengths of stay in the hospital and intensive care unit with high costs.
\end{abstract}

Aim of Study: The current study aimed to explore the risk factors of VAP among infants in Intensive Care Units.

Subjects and Methods: A descriptive exploratory design was used to achieve the current study.

Setting: The current study conducted at Pediatric Intensive Care Units at Pediatric University Hospital and Specialized Pediatric Hospital which affiliated to Cairo University Hospitals.

Sample: A convenience sample of 54 mechanically ventilated infants for more than 48 hours enrolled in the study.

Tools: The required data was collected by using risk factors assessment sheet and standardized observational checklists which consist of three parts: General infection control measures, nasogastric tube feeding and endotracheal tube suctioning.

Results: The current study results revealed that, more than half of infants were less than 6 months of age, nearly two-thirds are males, and near to three quarters of infants developed VAP. Prior antibiotic use, sedatives administration, absence of routine oral care, previous non-invasive ventilation, reintubation, length of stay on mechanical ventilation and PICUs, coma, inadequate general infection control measures, inadequate endotracheal tube suctioning technique, supine position, inadequate nasogastric tube feeding technique, presence of nasogastric tube and oral route of endotracheal tube were statistically significant risk factors associated with VAP. More than half of VAP infants died during period of hospitalization.

Correspondence to: Dr. Fatma E. Dagher,

The Department of Pediatric Nursing, Faculty of Nursing, Cairo University, Egypt
Conclusion: Prior antibiotic use was the only independent risk factor for incidence of VAP; and sedatives administration, absence of routine oral care, previous non-invasive ventilation, reintubation, length of stay on mechanical ventilation and PICUs were the major risk factors of VAP among infants in pediatric Intensive Care Units.

Recommendations: Inservice training program should be conducted for pediatric intensive care nurses about prevention of VAP among infants. Also, similar studies should be conducted on large sample and different settings.

Key Words: Pediatric intensive care unit-Mechanical ventilation - ventilator-associated pneumonia - Risk factors - Infants.

\section{Introduction}

INTENSIVE Care Units (ICUs) have the highest incidence of infections because of multiple risk factors, including frequent invasive procedures, use of medical devices, and prolonged exposure to multi-drug resistant organisms [1]. The percentage of pediatric patients requiring Mechanical Ventilation (MV) and hospitalized in ICU varies between $30 \%$ and $64 \%$; MV is a life-support therapy aimed at maintaining adequate alveolar ventilation and effective gas exchange in critically ill patients [2]. One of the most commonly associated encountered hospital acquired infections in respiratory Intensive Care Unit is Ventilator Associated Pneumonia (VAP) and it is associated with significant morbidity, mortality and high costs, VAP is defined as nosocomial pneumonia occurring after 48 hours from intubation and mechanical ventilation [3]. In the same context, VAP defined as a respiratory infection caused by micro-aspiration of organisms, 48 hours after going under mechanical ventilation [4]. 
Ventilator associated pneumonia is the second most common nosocomial infection in Pediatric Intensive Care Units (PICUs) accounting for $20 \%$ of all nosocomial infections in the pediatric population; the incidence of VAP varies worldwide, ranging from 1.7 to 8.9 per 1000 ventilator days [5]. VAP is a marked health risk for hospitalized infants and children. It is one of the top causes of hospital-acquired infections in PICUs, accounting for $18 \%$ to $26 \%$ of all hospital-acquired infections in the Intensive Care Units [6]. In Egypt, the incidence of VAP ranged from $16 \%$ to $75 \%$, with the lowest ratio in Alexandria University Hospital and the highest one in Ain Shams University Hospital, while the incidence in Mansoura University Hospital was $22.6 \%$ [7]. Moreover, [8] reported that, in 2011, an estimated 157,000 healthcare-associated pneumonias occurred in acute care hospitals in USA; $39 \%$ of these pneumonias were VAP. In the same context, pneumonia is the single largest infectious cause of death in children worldwide

Ventilator associated pneumonia is divided into early onset VAP and late onset VAP; early onset VAP is defined as pneumonia that occurs within 4 days of intubation and this is usually due to antibiotic sensitive pathogens, whereas late onset VAP is more likely caused by multidrug resistant bacteria and develops after five or more days of intubation [10].The duration of mechanical ventilation influences the type of causative organism and late onset VAP is caused by multi-drug resistant bacteria and the ones which are more difficult to treat [11].

Infants are at greater risk than older children for development of respiratory infections because of their immature immune system, smaller upper and lower airways, and under developed supporting cartilage [12] . Risk factors for pediatric VAP are prolonged mechanical ventilation, immunodeficiency, steroids, reintubation, primary blood stream infection, altered mental status, severe traumatic brain injury, burn injury, sedatives administration, and congenital neuromuscular weakness [13]. In the same context, [14] found that, prolonged ventilation and repeated intubations are the major risk factors for development of VAP.

In an Egyptian study conducted in the PICUs of Pediatric University Hospital, reported that supine position, neurological and neuromuscular diseases, prolonged duration of ventilation were independent risk factors for VAP, the overall mortality was $46.15 \%$, VAP mortality rate patients was higher $83.3 \%$ than non-VAP patients $35.1 \%$, the overall mean ventilation duration was 10.89 days and the overall mean length of stay was 12.77 days and recommend for additional studies estimating risk factors and outcome of VAP are needed in wide sample scale [15].

The prevention of VAP is primarily the responsibility of the bedside nurse whose knowledge, beliefs, and practices influence the health outcome of ICUs children. Critical care nurses play an important role in identification of risk factors and prevention of VAP. In Egypt; where there is shortage of nursing staff, skilled and knowledgeable nurses are extremely important and needed to make appropriate decisions in children care and minimize risks to children. Knowledge on evidence based practices should bring confidence to intensive care nurses to make appropriate decisions and prevent poor outcomes in the recovery of mechanically ventilated patients [16].

\section{Subjects and Methods}

Research question: What are the risk factors of VAP among infants in Intensive Care Units?

Research design: A descriptive exploratory design was utilized in the current study.

Setting: The proposed study was conducted at two hospitals which affiliated to Cairo University Hospitals:

1- Pediatric University Hospital where PICU is situated in the seventh floor that consists of two parts; the first part contains 13 beds for different diagnoses ( 3 beds for isolated cases, 3 resuscitation beds for young infants and another 7 beds for older children), and the second part contains 5 beds also for different diagnoses ( 3 resuscitation beds and 2 beds for older children) and this unit contains 25 mechanical ventilators.

2- Specialized Pediatric Hospital where there were three PICUs; the first one in the fourth floor consists of 14 beds for medical and surgical diagnoses ( 3 resuscitation beds for young infants and another 11 beds for older children) and this unit have 27 mechanical ventilators; the second one in the six floor which consists of two parts, the first part contains 7 beds for medical and surgical diagnoses for older children and the second part contains 4 resuscitation beds for young infants and another 2 beds for older children, as well as this unit have 16 mechanical ventilators, the last one was the emergency unit in the first floor which consists of 17 beds ( 7 resuscitation beds for young infant, and 
10 beds for older children) which receives different medical and surgical diagnoses and contains 29 mechanical ventilators.

Sample: A convenience sample of 54 infants on mechanical ventilation who were eligible for the following inclusion criteria; infants intubated for more than 48 hours, infants having the following criteria were excluded; infants already having pneumonia at the time of admission, infants who developed pneumonia in the first 48 hours of mechanical ventilation and infants connected with tracheostomy for mechanical ventilation. The data collection conducted over duration of six months from October 2016 to April 2017.

\section{Data collection tools:}

The required data was collected through the following tools;

\section{Tool 1:}

Risk factors assessment sheet was developed by the research investigator in English language after extensive review of related recent literature; it was consisted of two parts, part 1: To assess infant personal data and medical history, part 2: To assess factors affecting development of ventilator associated pneumonia.

- Part (1):

- Personal data sheet for infant: It involved age, gender, residence, date of admission at hospital, date of admission at pEdiatric Intensive Care Unit, and referred from where.

- Medical history: It involved temperature, white blood cells result, chest X-ray result, and clinical respiratory signs and symptoms (new onset of purulent sputum or change in character of sputum, or increased respiratory secretions or increased suctioning requirements and worsening gas exchange).

- $\operatorname{Part}(H)$ :

Risk factors assessment questionnaire; that was covered:

- Infants related factors: It involved previous illness, admission weight, current weight, diagnosis, level of consciousness, and length of stay in Pediatric Intensive Care Unit.

- Health care related factors:It involved invasive procedures done during hospitalization, oral care, method of feeding, normal saline used during suction, presence of nasogastric tube, sedative use, and prior antibiotic use.
- Mechanical ventilation related factors: It involved previous intubation and previous non-invasive ventilation, place of recent intubation, mode of $\mathrm{MV}$, route of intubation, the sterilization of circuit, infants' position on mechanical ventilator, reintubation, and length of hospital stay on MV.

Tool 2: Standardized observational checklists which used to assess nurses' skills:

- General infection control assessment sheet for personnel in contact with the infant: Adopted from [17] to assess environment and nurses' performance regarding aseptic technique while dealing with the infant such as hand hygiene performed before contact with infant and before leaving the infant's environment, sterile water for oxygen humidifier and gloves are worn when in contact with respiratory secretions and changed before contact with another patient, object, or environmental surface... etc.

- Nasogastric tube feeding checklist: Adopted from [18] and consisted of 17 steps about standardized technique of nasogastric tube feeding such as check order for type, amount, and order for feeding, assess the child respiratory status and color, and check for gastric residuals... etc.

- Endotracheal suctioning checklist: Adopted from [18] and involved 16 steps about proper technique of endotracheal suctioning such as dominant hand sterile and non dominant hand cleans for the procedure, using the dominant hand to manipulate the catheter and suction for less than 5 seconds... etc.

\section{Scoring system of checklists:}

Standardized observational checklists scored as follows, each correct step was given one point and zero if the step not done or done incorrectly. The observational checklists were done 3 times for each procedure. The scores of the items were summed-up and the total divided by the number of the items, giving a mean score for the part. These scores were converted into percent. The practice was considered adequate if the percent was $90 \%$ or more and inadequate if less than $90 \%$. This high cutoff point was set because of the critical conditions of the infants under the study and the importance of highly quality nurses' practices in this situation.

Tool validity:

Risk factor assessment sheet was given to a group of 3 experts in the field of pediatric nursing to test the content validity and minor modifications were done. 


\section{Reliability of checklists:}

Reliability of the tool was tested statistically using Cronbach's alpha, to insure its consistency; it was 0.7 which means high internal consistency, and consequently high reliability.

\section{Pilot study:}

The pilot study was carried out on 6 infants from the total sample to test study tools in terms of its clarity, applicability, objectivity and explain any discrepancies in the tools and time required to fulfill it. The needed modifications done, and then the final format were developed. The pilot study included in the study.

\section{Ethical considerations:}

Primary approval was obtained from the Research Ethical Committee in the Faculty of Nursing, Cairo University. A written informed consent was obtained from the parent of the infants and nurses assigned to the infants by the research investigator after complete description of the purpose and nature of the study in order to obtain their acceptance as well as to gain their cooperation. Parents were informed about their voluntary participation and their right to withdrawal from the study at any time. Also parents were assured that all gathered information will be confidential and will be used only for the purpose of the study.

\section{Procedure:}

After the ethical approval obtained from the Ethical Committee, an official permission was attained from the directors of Specialized Pediatric Hospital and Pediatric University Hospital as well as the heads of PICUs. The research investigator introduced herself to the parents of infants eligible for inclusion criteria and assigned nurse after complete description of the purpose and nature of the study to attain their acceptance and cooperation. Risk factors assessment sheet used to assess infants during the period of hospitalization in PICUs. The research investigator assessed any change in clinical sign and symptoms of the infants; especially respiratory signs and symptoms, followup of temperature changes begin from the time of intubation using the same thermometer every time for every infant. Radiological studies (mainly chest $\mathrm{X}$-ray), lab investigations (mainly white blood cells and sputum cultures), medication prescribed to the infants, and nursing notes checked by the research investigator from the time of intubation as base line data assessment till the infants discharged or referred or died. Any changes indicating that the infant developed VAP or not were recorded.
Also, standardized observational checklists (general infection control assessment sheet for personnel in contact with the infant, nasogastric tube feeding checklist and endotracheal suctioning checklist) were used to collect the study data through observing care provided to the infant for three interrupted times for every infant eligible for inclusion criteria; first time assessment was at the first day of initiation of mechanical ventilation to collect baseline data, the second time after two days from intubation, and third time at the fifth day from intubation. These three times helped the research investigator to determine the level of care provided by different nurses at different times. When the child developed VAP in the first 48 hours from intubation; the infant excluded from the study. The research investigator was available for data collection three days per week in different shifts (morning, afternoon, night shift). Data collection was conducted over six months from October 2016 to April 2017.

\section{Statistical analysis:}

The collected data categorized, tabulated and summarized. Data entry and statistical analysis were done using Statistical Package for Social Studies (SPSS) Version 20.0 statistical software package. Data were presented using descriptive statistics in the form of frequencies and percentages for qualitative variables, and means and standard deviations and medians for quantitative variables. Quantitative continuous data were compared using Student $t$-test in case of comparisons between two independent groups and paired $t$ test for dependent groups. When normal distribution of the data could not be assumed, the nonparametric Mann-Whitney or Kruskal-Wallis test was used instead of Student $t$-test. Qualitative categorical variables were compared using chisquare test. Whenever the expected values in one or more of the cells in a $2 \times 2$ tables was less than 5, Fisher exact test was used instead. In larger than $2 \times 2$ cross-tables, no test could be applied whenever the expected value in $10 \%$ or more of the cells was less than 5. To identify the independent predictors of the risk of VAP, multiple logistic regression analysis was used. Statistical significance was considered at $p$-value $<0.05$.

\section{Results}

Table (1) shows that, $53.7 \%$ of infants are less than 6 months of age, $64.8 \%$ are males, $68.5 \%$ are from rural areas, and $72.2 \%$ of infants developed VAP. 
Table (1): Percentage distribution of personal characteristics of study sample $(n=54)$.

\begin{tabular}{lcc}
\hline Infants' personal data & No. & $\%$ \\
\hline Infant age (months): & & \\
1-6 & 29 & 53.7 \\
$\quad$ or more & 25 & 46.3 \\
$\quad$ & & \\
Gender: & 35 & 64.8 \\
$\quad$ Male & 19 & 35.2 \\
Female & & \\
Residence: & 37 & 68.5 \\
$\quad$ Rural & 17 & 31.5 \\
$\quad$ Urban & & \\
$\quad$ Ventilator associated pneumonia: & 39 & 72.2 \\
$\quad$ Yes & 15 & 27.8 \\
$\quad$ No & & \\
\end{tabular}

Table (2) demonstrates that regarding personal characteristics of VAP infants, $56.4 \%$ and $64.1 \%$ of them their age less than 6 months and males, respectively and $71.8 \%$ from rural areas. Regarding the health history of VAP infants, $30.8 \%$ of them have previous illness with history of previous hospitalization, the mean admission and current weight is the same with $\mathrm{X} \pm \mathrm{SD}=5.7 \pm 2.2,43.6 \%$ of VAP infants have not weight gain, $87.2 \%$ are comatose and the mean length of stay in pediatric Intensive Care Units by days in VAP infants is more than non VAP infants with highly significant differences at $p=0.004 \&<0.001$, respectively. The same table shows that there are no statistically significant differences between VAP and non VAP infants regarding all personal characteristics.

Table (2): Relationships between personal characteristics, health history among Infants and VAP development $(\mathrm{n}=54)$.

\begin{tabular}{|c|c|c|c|c|c|c|}
\hline \multirow{3}{*}{ Infants' related factors } & \multicolumn{4}{|c|}{ VAP } & \multirow{3}{*}{$\chi^{2}$} & \multirow{3}{*}{$p$} \\
\hline & \multicolumn{2}{|c|}{ Yes $(n=39)$} & \multicolumn{2}{|c|}{ No $(n=15)$} & & \\
\hline & No. & $\%$ & No. & $\%$ & & \\
\hline \multicolumn{7}{|l|}{ Infant age (months): } \\
\hline $1-6$ & 22 & 56.4 & 7 & 46.7 & 0.41 & 0.52 \\
\hline 6 or more & 17 & 43.6 & 8 & 53.3 & & \\
\hline Mean \pm SD & \multicolumn{2}{|c|}{$5.3 \pm 3.0$} & \multicolumn{2}{|c|}{$6.3 \pm 3.2$} & $t=0.95$ & 0.33 \\
\hline \multicolumn{7}{|l|}{ Gender: } \\
\hline Male & 25 & 64.1 & 10 & 66.7 & & \\
\hline Female & 14 & 35.9 & 5 & 33.3 & 0.03 & 0.86 \\
\hline \multicolumn{7}{|l|}{ Residence: } \\
\hline Rural & 28 & 71.8 & 9 & 60.0 & & \\
\hline Urban & 11 & 28.2 & 6 & 40.0 & Fisher & 0.52 \\
\hline \multicolumn{7}{|l|}{ Previous illness with history } \\
\hline of previous hospitalization: & & & 5 & 33.3 & Fisher & 1.00 \\
\hline Yes & 12 & 30.8 & 10 & 66.7 & & \\
\hline No & 27 & 69.2 & & & & \\
\hline \multicolumn{7}{|l|}{ Admission weight $(\mathrm{kg})$ : } \\
\hline Mean \pm SD & \multicolumn{2}{|c|}{$5.7 \pm 2.2$} & \multicolumn{2}{|c|}{$6.5 \pm 1.9$} & $t=1.37$ & 0.24 \\
\hline \multicolumn{7}{|l|}{ Current weight ( $\mathrm{kg}$ ): } \\
\hline Mean \pm SD & \multicolumn{2}{|c|}{$5.7 \pm 2.2$} & \multicolumn{2}{|c|}{$6.6 \pm 1.9$} & & \\
\hline Median & \multicolumn{2}{|c|}{6.45} & \multicolumn{2}{|c|}{5.20} & $\mathrm{U}=1.35$ & 0.25 \\
\hline \multicolumn{7}{|l|}{ Weight gain: } \\
\hline Yes & 22 & 56.4 & 6 & 40.0 & & \\
\hline No & 17 & 43.6 & 9 & 60.0 & 1.17 & 0.28 \\
\hline \multicolumn{7}{|l|}{ Level of consciousness: } \\
\hline Confused & 5 & 12.8 & 8 & 53.3 & & \\
\hline Comatose & 34 & 87.2 & 7 & 46.7 & Fisher & $0.004 *$ \\
\hline \multicolumn{7}{|l|}{ Length of stay in PICUs: } \\
\hline$<7$ days & 4 & 10.3 & 7 & 46.7 & & \\
\hline$>7$ days & 35 & 89.7 & 8 & 53.3 & Fisher & $0.007 *$ \\
\hline Mean \pm SD & \multicolumn{2}{|c|}{$18.8 \pm 11.9$} & \multicolumn{2}{|c|}{$8.1 \pm 5.3$} & & \\
\hline Median & \multicolumn{2}{|c|}{7.0} & \multicolumn{2}{|c|}{16.0} & $\mathrm{U}=14.17$ & $\leq 0.001 * *$ \\
\hline
\end{tabular}


Table (3) clarifies that health care related factors among VAP infants, $61.5 \%$ of them do not receive routine oral care, while $93.3 \%$ of non VAP infants receive oral care, $84.6 \%$ received parentral nutrition, $64.1 \%$ have nasogastric tube, while $66.7 \%$ of non VAP infants do not have nasogastric tube, $97.4 \%$ of VAP infants have suction with normal saline to dissolve secretions, $46.2 \%$ and $43.6 \%$ respectively receive continuous and bolus sedation, and $74.4 \%$ have prior antibiotic use. Regarding invasive procedures; $69.2 \%$ of VAP infants have central venous line and $28.2 \%$ have urinary catheter. The same table reveals that there are statistically significant differences between VAP and non VAP infants regarding oral care, presence of nasogastric tube, prior antibiotic use, and sedatives administration, while there are no statistically significant differences between two groups regarding methods of feeding, using normal saline during suction and invasive procedures.

Table (3): Relationship between health care related factors and VAP development $(n=54)$.

\begin{tabular}{|c|c|c|c|c|c|c|}
\hline \multirow{3}{*}{ Health care related factors } & \multicolumn{4}{|c|}{ VAP } & \multirow{3}{*}{$x^{2}$} & \multirow{3}{*}{$p$} \\
\hline & \multicolumn{2}{|c|}{ Yes $(n=39)$} & \multicolumn{2}{|c|}{ No $(n=15)$} & & \\
\hline & No. & $\%$ & No. & $\%$ & & \\
\hline \multicolumn{7}{|c|}{ Oral care using normal saline: } \\
\hline Yes & 15 & 38.5 & 14 & 93.3 & & \\
\hline No & 24 & 61.5 & 1 & 6.7 & 13.12 & $\leq 0.001 * *$ \\
\hline \multicolumn{7}{|l|}{ Methods offeeding @: } \\
\hline Enteral & 17 & 84.6 & 12 & 80.0 & Fisher & 0.70 \\
\hline Parenteral & 33 & 43.6 & 5 & 33.3 & 0.47 & 0.49 \\
\hline $\mathrm{NPO}$ & 16 & 41.0 & 8 & 53.3 & 0.66 & 0.41 \\
\hline \multicolumn{7}{|l|}{ Presence of nasogastric tube: } \\
\hline Yes & 25 & 64.1 & 5 & 33.3 & & \\
\hline No & 14 & 35.9 & 10 & 66.7 & 4.15 & $0.04 *$ \\
\hline \multicolumn{7}{|c|}{$\begin{array}{l}\text { Normal saline used for dissolving } \\
\text { secretions during suction: }\end{array}$} \\
\hline Yes & 38 & 97.4 & 14 & 93.3 & Fisher & 0.48 \\
\hline No & 1 & 2.6 & 1 & 6.7 & & \\
\hline \multicolumn{7}{|l|}{ Sedatives administration: } \\
\hline None & 4 & 10.2 & 7 & 46.7 & & \\
\hline Continuous & 18 & 46.2 & 0 & 0.0 & 14.20 & $0.001 * *$ \\
\hline Bolus & 17 & 43.6 & 8 & 53.3 & & \\
\hline \multicolumn{7}{|l|}{ Prior antibiotic use: } \\
\hline Yes & 29 & 74.4 & 2 & 13.3 & & \\
\hline No & 10 & 25.6 & 13 & 86.7 & 16.50 & $\leq 0.001 * *$ \\
\hline \multicolumn{7}{|l|}{ Invasive procedures: } \\
\hline Central venous line & 27 & 69.2 & 7 & 46.7 & 2.37 & 0.12 \\
\hline Surgery & 3 & 7.7 & 2 & 13.3 & Fisher & 0.61 \\
\hline Chest tube & 6 & 15.4 & 0 & 0.0 & Fisher & 0.17 \\
\hline Dialysis & 2 & 5.1 & 0 & 0.0 & Fisher & 1.00 \\
\hline Urinary catheter & 11 & 28.2 & 3 & 20.0 & & \\
\hline Blood transfusion & 6 & 15.4 & 1 & 6.7 & 1.42 & 0.49 \\
\hline
\end{tabular}

Table (4) highlights that mechanical ventilation related factors are, $10.3 \%$ and $69.2 \%$ respectively of VAP infants have previous intubation and previous non-invasive ventilation, while all non VAP infants do not receive previous intubation and $80 \%$ do not have previous non-invasive ventilation, $66.7 \%$ of infants intubated in pediatric intensive care units of both group, $94.9 \%$ orally intubated, $94.9 \%$ are on synchronized intermittent mandatory ventilation mode, and $25.6 \%$ have reused after sterilization circuit type. Regarding position on ventilator, $28.2 \%$ of VAP infants are on supine position, $53.8 \%$ of them have the experience of reintubation for at least one time during period of mechanical ventilation, the mean length of stay of VAP infants on mechanical ventilation with $X \pm$ SD is $16 \pm 11.2$ days. The same table shows that there are statistically significant differences between VAP and non VAP infants regarding all mechanical ventilation related factors except previous intubation, place of recent intubation, mode of mechanical ventilator and circuit type. 
Table (4): Relationship between mechanical ventilation related factors and VAP development $(n=54)$.

\begin{tabular}{|c|c|c|c|c|c|c|}
\hline \multirow{3}{*}{ MV related factors } & \multicolumn{4}{|c|}{ VAP } & \multirow{3}{*}{$x^{2}$} & \multirow{3}{*}{$p$} \\
\hline & \multicolumn{2}{|c|}{ Yes $(n=39)$} & \multicolumn{2}{|c|}{ No $(n=15)$} & & \\
\hline & No. & $\%$ & No. & $\%$ & & \\
\hline \multicolumn{7}{|l|}{ Previous intubation within preceding } \\
\hline \multicolumn{7}{|l|}{30 days: } \\
\hline$\bullet$ Yes & 4 & 10.3 & 0 & 0.0 & & \\
\hline$\bullet$ No & 35 & 89.7 & 15 & 100 & Fisher & 0.57 \\
\hline \multicolumn{7}{|l|}{ Previous non-invasive ventilation: } \\
\hline •Yes & 27 & 69.2 & 3 & 20.0 & & \\
\hline$\bullet$ No & 12 & 30.8 & 12 & 80.0 & 10.63 & $0.001 * *$ \\
\hline \multicolumn{7}{|l|}{ Place of recent intubation: } \\
\hline • Intensive care unit & 26 & 66.7 & 10 & 66.7 & & \\
\hline • Emergency room & 6 & 15.4 & 3 & 20.0 & - & - \\
\hline • Ward & 5 & 12.8 & 1 & 6.7 & & \\
\hline - Operation room & 2 & 5.1 & 1 & 6.7 & & \\
\hline \multicolumn{7}{|l|}{ Route of intubation: } \\
\hline$\bullet$ Oral & 37 & 94.9 & 11 & 73.3 & & \\
\hline - Nasal & 2 & 5.1 & 4 & 26.7 & Fisher & $0.04 *$ \\
\hline \multicolumn{7}{|l|}{ Mode of mechanical ventilator: } \\
\hline $\begin{array}{l}\text { - Synchronized intermittent } \\
\text { mandatory ventilation }\end{array}$ & 37 & 94.9 & 14 & 93.3 & & \\
\hline $\begin{array}{l}\text { - Continuous positive airway } \\
\text { pressure }\end{array}$ & 1 & 2.6 & 0 & 0.0 & - & - \\
\hline - Continuous mandatory ventilation & 0 & 0.0 & 1 & 6.7 & & \\
\hline - Others & 1 & 2.6 & 0 & 0.0 & & \\
\hline \multicolumn{7}{|l|}{ Circuit type (tubes of ventilator): } \\
\hline - Reused after sterilization & 10 & 25.6 & 3 & 20.0 & & \\
\hline • Disposable & 29 & 74.4 & 12 & 80.0 & Fisher & 1.00 \\
\hline \multicolumn{7}{|l|}{ Position on ventilator: } \\
\hline - Supine & 11 & 28.2 & 0 & 0.0 & & \\
\hline - Semi-sitting & 28 & 71.8 & 15 & 100 & Fisher & $0.02 *$ \\
\hline \multicolumn{7}{|l|}{ Reintubation: } \\
\hline$\bullet$ Yes & 21 & 53.8 & 5 & 0.0 & & \\
\hline$\bullet$ No & 18 & 46.2 & 15 & 100 & 13.22 & $\leq 0.001 * *$ \\
\hline \multicolumn{7}{|l|}{$\begin{array}{l}\text { Length of stay on mechanical } \\
\text { ventilation: }\end{array}$} \\
\hline$\bullet<7$ days & 8 & 20.5 & 14 & 93.3 & & \\
\hline$\bullet>7$ days & 31 & 79.5 & 1 & 6.7 & 23.79 & $\leq 0.001 * *$ \\
\hline - Mean \pm SD & \multicolumn{2}{|c|}{$16.0 \pm 11.2$} & \multicolumn{2}{|c|}{$4.8 \pm 1.3$} & & \\
\hline • Median & \multicolumn{2}{|c|}{4.00} & \multicolumn{2}{|c|}{12.00} & $\mathrm{U}=21.4$ & $\leq 0.001 * *$ \\
\hline
\end{tabular}

$*: p<0.05$, significant.

$* *: p<0.001$, highly significant.

Table (5) illustrates that, 53.8\%, 51.3\% and $92.0 \%$ respectively of VAP infants receives inadequate general infection control measures, inadequate endotracheal suctioning technique and nasogastric tube feeding technique, while $93.3 \%$,
$86.7 \%$, and $60 \%$ among non VAP infants receive adequate general infection control measures, endotracheal suctioning and nasogastric tube feeding technique respectively, as well as the differences between the two group are statistically significant. 
Table (5): Relationship between nursing care provided to the Infants and VAP development $(n=54)$.

\begin{tabular}{|c|c|c|c|c|c|c|}
\hline \multirow{3}{*}{ Nursing care provided } & \multicolumn{4}{|c|}{ VAP } & \multirow{3}{*}{$x^{2}$} & \multirow{3}{*}{$p$} \\
\hline & \multicolumn{2}{|c|}{ Yes $(n=39)$} & \multicolumn{2}{|c|}{ No $(n=15)$} & & \\
\hline & No & $\%$ & No & $\%$ & & \\
\hline \multicolumn{7}{|l|}{ General infection control: } \\
\hline Average score: & $(n=39)$ & & $(n=15)$ & & & \\
\hline Competent & 18 & 46.2 & 14 & 93.3 & & \\
\hline Incompetent & 21 & 53.8 & 1 & 6.7 & 9.99 & $0.002 *$ \\
\hline \multicolumn{7}{|l|}{ Endotracheal suction: } \\
\hline Average score: & $(n=39)$ & & $(\mathrm{n}=15)$ & & & \\
\hline Competent & 19 & 48.7 & 13 & 86.7 & & \\
\hline Incompetent & 20 & 51.3 & 2 & 13.3 & 6.46 & $0.01 *$ \\
\hline \multicolumn{7}{|l|}{ Nasogastric tube feeding: } \\
\hline Average score: & $(n=25)$ & & $(n=5)$ & & & \\
\hline Competent & 2 & 8.0 & 3 & 60.0 & & \\
\hline Incompetent & 23 & 92.0 & 2 & 40.0 & Fisher & $0.02 *$ \\
\hline
\end{tabular}

Table (6) represents that, $56.4 \%$ of VAP infants died during period of hospitalization and there is no statistically significant difference when compared with non VAP infants.

Table (6): Relationship between incidence of VAP and outcome among infants $(n=54)$.

\begin{tabular}{|c|c|c|c|c|c|c|}
\hline \multirow{3}{*}{$\begin{array}{l}\text { Infants' } \\
\text { outcomes }\end{array}$} & \multicolumn{4}{|c|}{ VAP } & \multirow{3}{*}{$x^{2}$} & \multirow{3}{*}{$p$} \\
\hline & \multicolumn{2}{|c|}{ Yes $(n=39)$} & \multicolumn{2}{|c|}{ No $(n=15)$} & & \\
\hline & No & $\%$ & No & $\%$ & & \\
\hline \multicolumn{7}{|l|}{ Outcome: } \\
\hline Alive & 17 & 43.6 & 6 & 40.0 & & \\
\hline Dead & 22 & 56.4 & 9 & 60.0 & 0.06 & 0.81 \\
\hline
\end{tabular}

\section{Discussion}

The study results revealed that nearly three quarters of the study sample developed VAP after 2 days from initiation of mechanical ventilation, these results supported by $[\mathbf{1 9 , 2 0 ]}$ in a study titled "Ventilator associated Pneumonia in critically ill neonates admitted to neonatal intensive care unit, Zagazig University Hospitals" who found that, more than half of study sample developed VAP after 2 days from initiation of mechanical ventilation. This could be interpreted as; infants are more risky for VAP because of immaturity of immune system and majority of body systems. Moreover, the rate of VAP increased or decreased according to facilities of units, so in PICUs, there are shortages of nursing staff and supplies, and lack of inservice training program for nurses; all these factors may predispose to VAP development among infants.
The present study results showed that the mean age of VAP infants was less than mean age of non VAP infants, these results were in accordance with [21], and also with [22] who found that, the children who developed VAP were significantly younger compared with other ages. Additionally, the study done by [23] in Pakistan about "ventilator associated pneumonia in children" who reported that, almost half of VAP patients were younger than 1 year. The present study results clarified that nearly twothirds of VAP infants were males; these results were in agreement with [19] who reported that, nearly three quarters of VAP cases were males. Also, [20] found that, more than half of VAP infants were males. This could be interpreted as; there are no great differences in body structures and organ development between both sexes in infancy and early childhood but male gender still considered high risk group.

The present study results showed that twothirds of VAP infants' families were from rural areas. This may be due to, the university hospitals considered the largest children's hospitals in Egypt which containing different specialties, also, VAP is a hospital acquired infection that affected by the children environmental conditions inside the hospital.

The study results demonstrated that the mean score of admission weight of VAP infants was less than the mean score of non VAP infants, these results were in accordance with studies done by $[24,25]$ in Egypt who reported that, the mean admission weight of infants was less than the mean admission weight of non VAP infants. This could 
be interpreted as; body weight of neonates and infants is more critical indicator in which it reflects the overall health and nutritional status of infants, which made the infants risky to acquire infections. The current study results revealed that less than one third of VAP infants had previous illness with history of previous hospitalization; these results were in agreement with [26] who reported that, about one third of VAP infants had history of previous illness and hospitalization.

The study results demonstrated that the majority of VAP infants were comatose at the time of initiation of MV, these results supported by [22] who reported that, coma significantly associated with development of VAP. Also, [13,27] who found that, coma associated with increased risk of acquiring VAP. This could be interpreted as; comatose infants become more dependent on MV, stay more days in PICU, and need more invasive procedures such as frequent suctioning, and reintubation... etc. all maneuvers act as precipitating factors for developing VAP.

The study results showed that, nearly two-thirds of VAP infants did not receive routine oral care and the vast majority of non VAP infants received oral care by normal saline, these results supported by [28] in a study titled "mouth care to reduce ventilator associated pneumonia" who reported that, when oral care is not provided to a patient who is mechanically ventilated, this increases the opportunity of pathogens such as Klebsiella, Pseudomonas, and Escherichia coli to colonize the oropharyngeal site and routine oral care can prevent aspiration of these pathogens and prevent risk of aspiration of them to the lung subsequently prevent respiratory infections.

In the same context, these results were in agreement with [29] who documented that, the New Zealand Dental Association recommended the use of normal saline to perform the oral care in infants without dental eruption, as well as reported that, oral care decrease risk of acquiring VAP, also, [13] emphasized that, strategies documented to decrease risk of VAP in pediatrics include scheduled oral care. Furthermore, [6] emphasized to provide oral care every 2 hours using swabs soaked in saline for infants with no teeth.

The study results revealed that the majority of VAP infants received normal saline inside endotracheal tube prior to suction episode, these results were not in accordance with $[30,31]$ who recommended that, instillation of normal saline should not be routinely used. This could be interpreted as; normal saline instillation is used frequently by many nurses to get out the thick secretions and injection of anything inside the endotracheal tube may spread organisms downward to the lung. Therefore, use other alternatives for the management of thick secretions such as chest physiotherapy as it is safer to loose secretions instead of using normal saline instillation.

The study results found that nearly two-thirds of VAP infants had nasogastric tube either for decompression or for feeding; these results were in accordance with [24], also with [32] who mentioned that, the presence of nasogastric tube statistically significant risk factor of VAP. The current study results revealed that more than two-fifth of VAP infants received enteral feeding, these study results in accordance with [20] who reported that, more than half of VAP group received enteral feeding. Also, [5] found that, more than two-fifth of VAP group received enteral feeding. The study results revealed that the majority of VAP infants received parenteral nutrition, these results supported by $[33,34]$ who reported that, the higher percentage of VAP infants received parenteral nutrition and increased duration of parenteral nutrition associated with increased risk of VAP.

The study results proved that the majority of VAP infants received sedatives during the period of mechanical ventilation as well as nearly half of VAP infants received continuous sedation and more than two-fifths received bolus sedation, these results supported by [33] who reported that, nearly half of neonates received sedatives on MV. This could be interpreted as; sedatives especially continuous sedation decrease the chance of early weaning from MV so increase the dependency on MV, which increase the risk of VAP. Furthermore, sedatives increase the chance of aspiration due to decrease gut motility.

The study results showed that near to three quarters of VAP infants had prior antibiotic use just before and early days of mechanical ventilation and it significantly associated with increased risk of VAP, these results were in accordance with [11] who reported that, prior antibiotic therapy was a risk factor that can cause VAP due to multi-drug resistant organisms. A recent study done by [22] who found that, prior antibiotic use for $>48$ hours before MV was significantly associated with higher risk of VAP in which more than two-thirds of VAP children had prior antibiotics. On the same context, [27] reported that, prior antibiotic use was significant risk factor for developing VAP. 
The study results proved that more than twothirds of VAP infants had central venous line, these results supported by [13] who reported that, nearly two-thirds of VAP children have central venous line. This could be interpreted as; presence of central venous line may be associated with risk of VAP through indirect cause in which central venous line may increase risk of sepsis which negatively affects the child immunity and predispose to occurrence of VAP.

The current study results showed that the minority of VAP infants admitted to PICUs after postsurgical procedure, these results supported by $[19,33]$ who identified that, the minority of VAP infants admitted due to surgical causes. This could be interpreted as; VAP may be developed as complications post-operatively due to immobilization, improper nutrition and fluid volume deficit.

The current study clarified that less than one fifth of VAP infants received blood transfusion; these results were in accordance with [35] who reported that, blood transfusion was significant risk factor for VAP. While, the current results were not in accordance with [36] who reported that, there was no relation between blood transfusion and risk of VAP. The current study results revealed that the minority among VAP infants had chest tubes, these results supported by $[\mathbf{2 0 , 2 5 ]}$ who found that, one quarter of VAP infants had chest tubes.

The current study results proved that more than two-thirds of VAP infants had previous noninvasive ventilation; these results were in agreement with [37] who stressed that, more than half of VAP cases had the experience of previous non-invasive ventilation. The current study showed that more than one tenth of VAP infants had history of previous intubation in the preceding 30 days; these results were in agreement with [38] who reported that, $4.05 \%$ of children who had history of previous intubation and developed VAP.

The current study results clarified that twothirds of VAP and non VAP infants intubated in pediatric intensive care units and there was no relation between place of intubation and risk of VAP, these results supported by [39] who found that, location of intubation was not associated with VAP. This could be interpreted as; VAP rate depends on technique of intubation and a sepsis measures, so if the intubation done in well-prepared place and qualified personnel, this will lead to decrease the risk of VAP development. The current study results revealed that one quarter of VAP infants had reused circuit type after sterilization, these results supported by [26] who reported that, about one quarter of VAP infants had reused after sterilization circuit type. This could be interpreted as; using disposable circuit is safer more than reusable circuit.

The current study results clarified that the vast majority of VAP infants had oral endotracheal tube, these results supported by [36] who reported that, more than half of VAP children had oral ETT. Also, [40] found that, children with orotracheal tubes had a higher prevalence of aspiration compared with nasotracheally intubated and recommended the use of nasotracheal route for intubation in children. This could be interpreted as; colonized oral cavity may spread pathogens to oral ETT that bypass them to the lungs and this increase the chance of developing VAP especially in neonates and infants due to un-cuffed ETT. Also, neonates and infants likely at greater risk for aspiration of contaminated oral secretion as gastro-esophageal reflux common in infants.

The current study results proved that more than one quarter of VAP infants were lay on supine position, while all non VAP infants were on semisitting position, these results supported by [41] who emphasized that to place the ventilated patient in semi-upright position between 30 and 45 degrees unless contraindicated to reduce the risk of VAP. Also, these results supported by [42] who reported that, elevation head of bed in ventilated infants is needed to reduce risk of aspiration and VAP. This could be interpreted as; supine position may increase the risk of aspiration of colonized gastric content to the lung especially in un-cuffed ETT in younger children.

The current study results showed that more than half of VAP infants had the experience of reintubation for at least one time during recent hospitalization, these results were in accordance with [24] who reported that, all neonates with VAP reintubated for at least one time, also, [35] in a study titled "risk factors for ventilator-associated pneumonia in the neonatal Intensive Care Unit: A meta-analysis of observational studies" supported these results and reported that, reintubation significantly increased the risk of acquiring VAP. Furthermore, a study done by [43] about "study of ventilator associated pneumonia in neonatal Intensive Care Unit: Characteristics, risk factors and outcome" who found that, reintubation done among near to two-thirds of VAP neonates.

The current study results identified that VAP infants had significantly longer days on MV with 
mean score was $16 \pm 11.2$ day, these results were in accordance with [34] who reported that, neonates with VAP had longer stay in NICUs with mean score was $58.7 \pm 39.6$ day. Also, the current study results were in the same line with [19] who reported that, duration of ventilation was found to be significantly longer in infants with VAP with mean score was $26.0 \pm 11.5$ day. The study results illustrated that the majority of VAP infants had significantly longer length of stay in PICUs with mean days of stay was $18.8 \pm 11.9$, these results supported by [44] who mentioned that, VAP infants had significantly higher length of stay in pediatric Intensive Care Units with mean score was $14 \pm 12$ days.

The current study results showed that more than half of VAP infants received inadequate general infection control measures and the vast majority of non VAP infants received adequate infection control, these results were in accordance with $[27,45]$ who reported that, poor adherence to hand hygiene infection control processes can lead to cross contamination of organisms between children and this may contribute to VAP development. Also, the current study results were in accordance with a study done by [46] in Egypt about "reducing ventilator-associated pneumonia in neonatal Intensive Care Unit using VAP prevention bundle: A cohort study" who recommended that, hand hygiene is the most important infection control intervention in all health care setting and stated that applying bundle of infection control practices can effectively reduce the occurrence of VAP during neonatal ventilation period. In the same context, [47] discussed that; hand hygiene and staff's training are significantly correlated with decreased incidence of VAP. This could be interpreted as; the critical care units with its critical and invasive procedures require high precautions regarding application of universal infection control measures.

The present study results proved that more than half of VAP infants received inadequate endotracheal suctioning technique, these results supported by [27] who discussed that, endotracheal tubes may become contaminated when endotracheal suctioning become a routine care or via the contaminated hands of medical team members, also, these results were in the same line with [43] who discussed that, endotracheal suctioning is not mentioned in any research paper as a factor associated with VAP but on the other hand, it may be associated with contamination of airway and subsequent VAP can occur if proper practice is not established.

The current study results revealed that the vast majority of VAP infants received inadequate na- sogastric tube feeding technique, as well as, the research investigator observed that most nurses caring for the infants did not check the position of nasogastric tube and gastric residual before feeding, these results were in the same line with [48] who discussed that, performing routine gastric residual aspiration and evaluation prior to every feeding in critically ill infants prevent aspiration of gastric contents, which may contribute to VAP.

The current study results identified that prior antibiotic use considered the only independent risk factor for acquiring VAP. In the same context, [22] found that, prior antibiotic use $>48$ hours, multiple organ system failure, reintubation, coma and age in months were independent risk factors for VAP. Also, [37] reported that, previous use of one or more antibiotics and reintubation were independent risk factors for acquiring VAP in infants. On the other hand, [33] revealed that, duration of mechanical ventilation was independent and statistically significant risk factor for development of VAP. Moreover, [21] reported that, positive blood culture growth was the only independent risk factor associated with VAP.

The current study results answered the research question about the risk factors of VAP among infants in intensive care units and concluded that, the following factors were statistically significant risk factors associated with VAP; prior antibiotic use, sedatives administration, absence of routine oral care, previous non-invasive ventilation, reintubation, length of stay on mechanical ventilation and PICUs, coma, inadequate general infection control measures, inadequate endotracheal tube suctioning technique, supine position, inadequate nasogastric tube feeding technique, presence of nasogastric tube and oral route of endotracheal tube.

The current study results proved that, more than half of VAP infants died during the study period, these results were in agreement with [21] who reported that, near to half of VAP infants died from the study sample. Additionally, [22] reported that, more than two-thirds of VAP children died. This could be interpreted as; VAP increase mortality of infants if not early detected and well treated. So, early detection and proper treatment of organism based on culture and sensitivity test to choose proper antibiotics prevent complication of VAP that increases the mortality rate.

\section{Conclusion:}

In the light of study findings; prior antibiotic use was the only independent risk factor for inci- 
dence of VAP; and sedatives administration, absence of routine oral care, previous non-invasive ventilation, reintubation, length of stay on mechanical ventilation and PICUs were the major risk factors of VAP among infants in pediatric Intensive Care Units.

\section{Recommendations:}

Based on study findings; the current recommendations are suggested:

For pediatric hospitals:

- Providing enough and disposable medical supplies for pediatric Intensive Care Units.

- Inservice training program should be conducted for pediatric Intensive Care Nurses about prevention of VAP among infants.

- Posters and handouts should be placed within the PICUs to raise the awareness of nurses about evidence based guidelines and bundle of care for prevention of VAP.

- Primary prevention for VAP through controlling the associated risk factors.

For research:

- Similar studies should be conducted on large sample and different settings.

- Further studies in pediatrics are needed to determine the impact of using normal saline in suction on incidence of VAP.

- More studies about predictors of mortality in VAP infants in pediatric Intensive Care Units are needed.

\section{References}

1- VENKATACHALAM V., HENDLEY O. and WILLSON D.: The Diagnostic Dilemma of Ventilator-Associated Pneumonia in Critically Ill Children. Pediatric Critical Care Medicine, 12 (3): 286-96. Doi: 10.1097/ PCC.0b 013e3181fe2ffb, 2011.

2- VALENZUELA J., ARANEDA P. and CRUCES P.: Weaning From Mechanical Ventilation in Pediatrics. Archivos De Bronconeumology, 50: 105-12. Available at: www.archbronconeumol.org, 2014.

3- ISGUDER R., CEYLAN G., AG1N H., GULFIDAN G., AYHAN U. and DEVRIM L.: New Parameters for Childhood Ventilator Associated Pneumonia Diagnosis. Pediatric pulmonology, 52: 119-28. Doi 10.1002/ppul.23504, 2017.

4- BOZORGMEHR R., BAHRANI V. and FATEMI A.: Ventilator-Associated Pneumonia and its responsible germs; an Epidemiological Study. Emergency Journal; 5 (1): 1-26. Available at: www.ncbi.nlm.gov, 2017.

5- MORINEC J., IACABONI J. and Mc. NETT C.: Risk factors and interventions for Ventilator Associated Pneumonia in pediatric patients. Journal of Pediatric Nursing, 27: 435-42. Doi:10.1016/j.pedn.2010.07.010, 2012.
6- COOPER B. and HAUT C.: Protocol Preventing Ventilator Associated Pneumonia in Children: An Evidence-Based. American Association of Critical-Care Nurses, 33: 21-9. Available at: http://www.cconline.org, 2013.

7- FATHY A., ABDEL HAFEEZ R., EL-GILANY A. and ABD ELHAFEZ S.: Analysis of Ventilator Associated Pneumonia (VAP) Studies in Egyptian University Hospitals. Egyptian Journal of Chest Diseases and Tuberculosis 62: 17-25. Doi.org/10.1016/j.ejcdt.2013.04.008, 2013.

8- Centers for Disease Control and Prevention (CDC), Ventilator-Associated Pneumonia (VAP) event, Device Associated Module, 6: 11. Available at: http://www.cdc.gov/ nhsn/pdfs/pscmanual/6pscvapcurrent.pdf, 2017.

9- World Health Organization Media Centre (WHO), Pneumonia fact sheet 331. http://www.who.int/mediacentre/ factsheets/fs331/en/index.html. updated September 2016, 2016.

10- KALANURIA A., ZAI W. and MIRSKI M.: VentilatorAssociated Pneumonia in the ICU. Critical Care Journal, 18: 2-8. Available at: http://ccforum.com/content, 2014.

11-ANGAALI N., ROY N., CHITGUPIKA S., SUBRAMANIAN P. and PABBATI J.: Ventilator Associated Pneumonia in an Infant caused by Stenotrophomonas maltophila-A Case Report. Journal of Clinical and Diagnostic Research, 10 (9): 1-3. Doi: 10.7860/JCDR/2016/ 19822.8411, 2016.

12- MCKINNEY E., JAMES S., MURRAY S., NELSON K. and ASHWILLJ.: Maternal-Child nursing, 4 th ed., Elsevier, Saunders, Canada, 1143-50, 2013.

13- HAZINSIKI M.: Nursing Care of Critically Ill Child, 3 rd ed., USA, Elsevier, Mosby, 17-8, 2013.

14- VEDAVATHY S. and SANGAMESH: Clinical Study of Ventilator Associated Pneumonia in a Tertiary Care Centre. International Journal of Contemporary Pediatrics, 3 (2): 432-41. Available at: http://dx.doi.org , 2016.

15- HASSNEAN A.: Unpublished Master Thesis in Pediatric Medicine "Prevention of Ventilator Associated Pneumonia in Pediatric Intensive Care Unit", Cairo University, Egypt. 61-79, 2012.

16-AHMED G. and ABOSAMRA O.: Knowledge of Pediatric Critical Care Nurses regarding Evidence based Guidelines for Prevention of Ventilator Associated Pneumonia. Journal of Education and Practice, 6 (9): 94-101. Available at: www.iiste.org/Journals/index, 2015.

17- Centers for Medicare and Medicaid Services: Department of Health and Human Services. Infection control worksheet. Available at: https://www.cms.gov , 2016.

18- BALL J. and BINDLER R.: Clinical Skill Manual for Principle of Pediatric Nursing, 5 th ed., USA. 137-8, 2012

19- KHATTAB A., EL-LAHONY D. and SOLIMAN W.: Ventilator Associated Pneumonia in the Neonatal Intensive Care Unit. Menoufia Medical Journal, 27 (1): 73-7. Doi: 10.4103/1110-2098.132753, 2014.

20- BADR M., ALI Y., ALBANNA E., BESHIR M. and AMR G.: Ventilator Associated Pneumonia in Critically Ill Neonates admitted to Neonatal Intensive Care Unit, Zagazig University Hospitals. Iranian Journal of Pediatrics, 21 (4): 418-24. Available at: http://www.ncbi.nlm.nih.gov , 2011. 
21- BALASUBRAMANIAN P. and TULLU M.: Study of Ventilator-Associated Pneumonia in a Pediatric Intensive Care Unit. The Indian Journal of Pediatrics, 81 (11): 1182 6. Doi: 10.1007/s12098-014-1444-1, 2014.

22- GALAL Y., YOUSSEF R. and IBRAHIEM S.: VentilatorAssociated Pneumonia: Incidence, Risk Factors and Outcome in Pediatric Intensive Care Units at Cairo University Hospital. Journal of Clinical and Diagnostic Research, 10 (6): 6-11. Doi: 10.7860/JCDR/2016/18570.792, 2016

23- HAMID M., MALIK M., MASOOD J., ZIA A. and AHMAD T.: Ventilator-Associated Pneumonia in Children. Journal of the College of Physicians and Surgeons Pakistan, 22 (3): 155-8. Available at: https://jcpsp.pk/archive/ 2012/Mar2012/07, 2012.

24- EL-SEHEMAWY A., EL-DOSOKY M., EZZAT H. and EL-DOSOKY N.: Evaluation of Tumor Necrosis Factor Receptor 1 in Diagnosis of Ventilator-Associated Pneumonia. Clinical Medicine and Diagnostics, 6 (5): 111-21. Doi: 10.5923/j.cmd.20160605.01, 2016.

25- AFIFY M., AI-ZAHRANI S. and NOUH M.: Risk Factors for the Development of Ventilator-Associated Pneumonia in Critically-Ill Neonates. Life Science Journal, 9 (1): 302-7. Available at: http://www.lifesciencesite.com , 2012.

26- AWASTHI S., TAHAZZUL M., AMBAST A., GOVIL Y. and JAIN A.: Longer duration of Mechanical Ventilation was found to be associated with Ventilator-Associated Pneumonia in Children aged 1month to 12 years in India. Clinical Epidemiology Journal, 66: 62-6. Available at: http://dx.doi.org/10.1016/i.jclinepi.2012.06.006, 2013.

27- ELZOUKI Y., HARFI H., NAZER H., STAPLETON F., WILLIAM O. and WHITLEY R.: Textbook of Clinical Pediatrics, 2 nd ed., Springer, New York, London, P.P. 838-9, 2012.

28- STAJA B., SHARON M., LISA K. and RITA J.: Mouth Care to reduce Ventilator associated pneumonia. American Journal of Nursing, 113 (10): 24-30. Available at: www. nursingcenter.com, 2013.

29- RODRIGUEZ F., GONZALEZ P., CALVO M., SANCHEZ C. ALONSO P. and ROMERO D.: Oral Care in Neonatal Intensive Care Unit. The Journal of Maternal-Fetal, Neonatal Medicine, 30 (8): 953-7. Doi: 10.1080/14767058. 2016.1192599, 2017.

30- GONCAVLES R., TSUZUKI L. and CARVALHO M.: Endotracheal Suctioning in intubated Newborns: An integrative literature review. Revista Brasileria de Terapia Intensvia, 27 (3): 284-92. Available at: http://www.google. . com.eg, 2015.

31- American Association for Respiratory Care: AARC Clinical guidelines. Enotracheal Suctioning of Mechanically Ventilated Patients with Artificial Airways. Respiratory Care, 55 (6): 758-64. Available at: http://www.ncbi.nlm.nih.gov 2010.

32- MIR Z., ALI I., QURESHI O. and WANI G.: Risk Factors, Pathogen Profile and Outcome of Ventilator associated pneumonia in a Neonatal Intensive Care Unit. International Journal of Contemporary Pediatrics, 2 (1): 17-20. Doi: 10.5455/2349-3291.ijcp20150204, 2015.

33- THATRIMONTRICHAI A., RUJEERAPAIBOON N., JANJINDANAI W., DISSANEEVATE S., MANEENIL G., KRITSANEEPAIBOON S. and TANAANANTARAK P.: Outcomes and Risk Factors of Ventilator Associated
Pneumonia in Neonates. World Journal of pediatrics, 13 (4): 328-34. Doi: 10.1007/s125 19-017-0010-0, 2017.

34- LEE P., LEE W. and CHEN H.: Ventilator-Associated Pneumonia in low birth Weight Neonates at a Neonatal Intensive Care Unit: A Retrospective observational study. Pediatric and Neonatology, 58: 16-22. Doi. org/10.1016/ j.pedneo.2015.10.014, 2017.

35- TAN B., ZHANG F., ZHANG X., HUANG Y., GAO Y., LIU X. and QIU J.: Risk Factors for Ventilator-Associated Pneumonia in the Neonatal Intensive Care Unit: A metaanalysis of observational studies. European Journal of Pediatrics, 173: 427-34. Doi: 10.1007/s00431-014-22786, 2014.

36- CHIRU A., CRĂCIUN A., TEPENEU N., ŞIPOŞ C., BIZEREA T., GRECU A and CONSTANTIN I.: Incidence, Risk Factors, and Nosocomial Germs for VAP in Children. Jurnalul Pediatrlului, 16 (64): 3-8. Available at: http:// . web. a.ebscohost.com, 2013

37- PATRIA M., CHIDINI G., UGHI L., MONTANI C., PRANDI E., GALEONE C. and ESPOSITO S.: Ventilator Associated Pneumonia in an Italian Pediatric Intensive Care Unit. World Journal of Pediatrics, 9: 365-8. Available at: www.ncbi.nlm.nih.gov/pubmed, 2013.

38- GUPTA S., BOVILLE B., BLANTON R., LUKASIEWICZ G., WINCEK J., BAI C. and FORBES M.: A Multicentered Prospective Analysis of Diagnosis, Risk Factors, and Outcomes associated with Pediatric VentilatorAssociated Pneumonia. Pediatric Critical Care Medicine, 16 (3): 65-73. Doi: 10.1097/PCC.0000000000000338, 2015.

39- HAMELE M., STOCKMANN C., CIRULIS M., RIVACAMBRIN J., METZGER R., BENNETT T. and BRATTON S.: Ventilator-Associated Pneumonia in Pediatric Traumatic Brain Injury. Journal of Neurotrauma, 33: 8329. Doi: 10.1089/neu.2015.4004, 2016.

40- CHANG I. and SCHILBER A.: Ventilator-Associated Pneumonia in Children. Pediatric Respiratory Review, 20: 10-1. Doi: 10.1016/j.prrv.2015.09.005, 2016.

41- Scientific Committee on Infection Control (SCIC), Recommendations on prevention of Ventilator-Associated Pneumonia, 1-21. Available at: www.chp.gov.hk/files, 2010.

42- PARTHASARATHY A.: Textbook of Pediatric Infectious Diseases, New Delhi, India, 94-5, 2013.

43- TRIPATHI S., MALIK G., JAIN A. and KOHLI N.: A Study of Ventilator Associated Pneumonia in Neonatal Intensive Care Unit Characteristics, Risk Factors and Outcome. Internet Journal of Medical Update, 5: 12-9. Available at: http://www.akspublication.com/ijmu, 2010

44- AFJEH S., SABZEHEI M., KARIMI A., SHIVA F. and SHAMSHIRI A.: Surveillance of Ventilator associated pneumonia in neonatal Intensive Care Unit: Characteristics, risk factors, and outcome. Archives of Iranian Medicine, 15 (9): 568-71. Available at: www.ncbi.nlm.nih. gov, 2012

45- ERGUL A., CETIN S., ALTINTOP Y., BOZDEMIR S. OZCAN A., ALTUG U. and TORUN Y.: Evaluation of Microorganisms Causing Ventilator-Associated Pneumonia in a Pediatric Intensive Care Unit. Eurasian Journal of Medicine, 49: 87-91. Doi 10.5152/eurasianjmed.2017. $16262,2017$. 
46- AZAB S., SHERBINY H., SALEH S., ELSAEED W., ELSHAFIEY M., SIAM A. and GHEITH T.: Reducing Ventilator-Associated Pneumonia in Neonatal Intensive Care Unit using VAP Prevention Bundle: A Cohort Study, Bio. Med. Central. Infectious Diseases Journal, 15: 1-7. Doi: 10.1186/s12879-015-1062-1, 2015.

47- SHMILEV T. and YANKOV I.: Ventilator Associated Pneumonia in Children Prophylaxis and Treatment. Folia
Medical Journal, 54 (1): 12-8. Doi: 10.2478/v10153-0110072-z, 2012.

48- LESLIE P., MURGAS T, YUEFENG L., ELIZABETH T., JONATHAN S. and JOSEF N.: Aspiration and Evaluation of Gastric Residuals in the Neonatal Intensive Care Unit: State of the Science. Journal of Prenatal and Neonatal Nursing, 29 (1): 51-9. Available at: www.ncbi.nlm.gov, 2015.

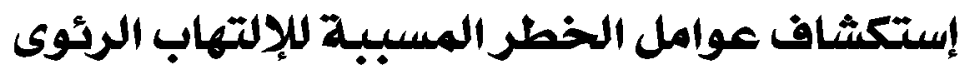 المصاحب لجهاز التثفس الصناعى بين الرضع فى وحدات العناية المركزة}

يعد الإلتهاب الرئوى المصاحب لجهاز التنفس الصناعى من عدوى المستشفيات المكتسبة والآكثر شيوعا فى وحدات العناية المركزة للآطفال.

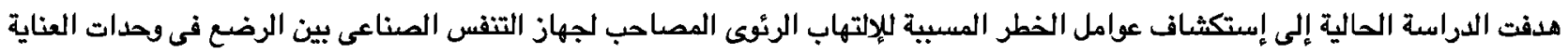

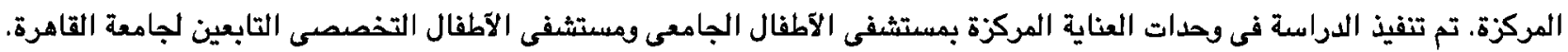

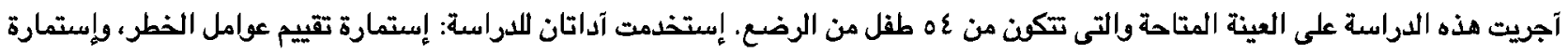

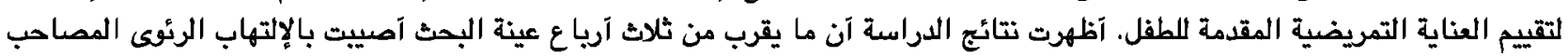

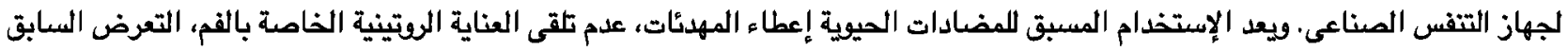

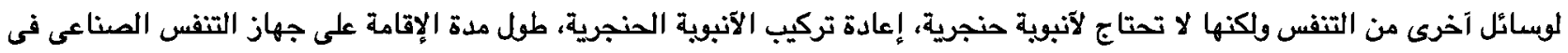

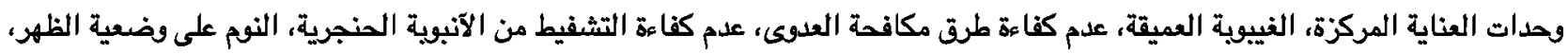

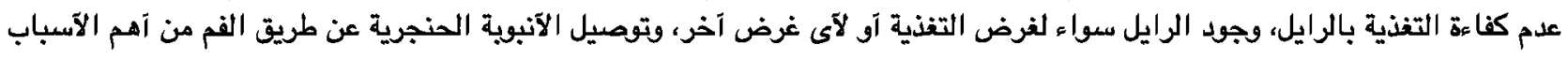

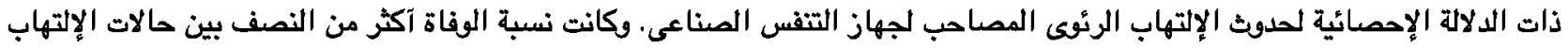
الرئوى المصاحب لجهاز التنفس الصناعى.

الخلاصة: توصلت الدراسة الحالية إلى آن الإستخدام المسبق للمضادات الحيوية هو العامل المستقل المسبب لحدوث الإلتهاب الرئوىى

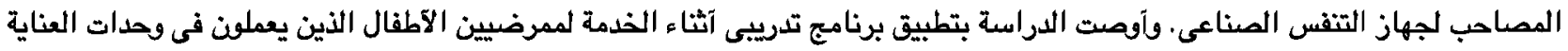
المركزة عن كيفية تجنب الإصابة بالإلتهاب الرئوى المصاحب لجهاز التنفس الصناعى. 